\title{
FREQUENCY OF EXCELLENT LARYNGEAL MASK AIRWAY INSERTION CONDITIONS IN CHILDREN UNDERGOING ELECTIVE SURGERY: A COMPARISON OF PROPOFOL WITH KETOFOL.
}

\footnotetext{
1. MBBS, FCPS

Assistant Professor Anesthesia \& Intensive Care

Aziz Fatimah Hospital, Faisalabad.

2. MBBS, FCPS

Senior Registrar Anesthesia \& Intensive Care

Aziz Fatimah Hospital, Faisalabad.

3. MBBS, MCPS

Senior Registrar Anesthesia \& Intensive Care

Abwa Hospital, Faisalabad.

4. MBBS, FCPS

Senior Registrar Anesthesia \&

Intensive Care

Allied Hospital, Faisalabad.

5. MBBS, FCPS

Assistant Professor Anesthesia \& Intensive Care

Abwa Hospital, Faisalabad.
}

Correspondence Address:

Dr. Humaira Ahmad

Anesthesia \& Intensive Care

Aziz Fatimah Hospital, Faisalabad.

humaira_ahmad21@hotmail.com

Article received on:

20/05/2019

Accepted for publication:

20/10/2019

\begin{abstract}
Humaira Ahmad ${ }^{1}$, Amna Tariq², Asif Sagheer ${ }^{3}$, Aisha Ahmad4, Samina Aslam ${ }^{5}$
\end{abstract}
ABSTRACT: Objectives: The laryngeal mask airway is used for provision of anesthesia for various surgical procedures as well as in emergency management of airway. It is a useful rescue tool in cases of failed intubation. Its insertion is associated with lesser complications. With advancement in medical equipment new versions of LMA with additional benefits are available. In this study evaluation of frequency of excellent LMA insertion conditions with use of ketofol or propofol as induction agent has to be evaluated. Purpose of the study is to identify which agent will provide favourable conditions for insertion, with least complications. Study Design: Randomized control trial. Setting: Departments of Anesthesia and Intensive Care Allied Hospital and Aziz Fatimah Hospital, Faisalabad. Period: From 01-01-2017 to 30-06-2018. Material \& Methods: Approval from ethical review committee was obtained. 230 children presenting for elective surgery were enrolled into study using non-probability consecutive sampling. Two groups consisting of 115 each were generated by randomization. Group P received propofol and Group PK received 2:1 propofol ketamine mixture. Ease of LMA insertion was assessed on the basis of degree of muscle relaxation and adverse reactions to LMA insertion. Data was collected and analysed using SPSS version 18. Results: Results were presented in terms of frequency of excellent LMA insertion conditions. It showed that ketofol provides better LMA insertion as compared to propofol alone with $p$ value of 0.007 , which is significant. Conclusion: The study concluded that use of ketofol provides excellent insertion conditions for LMA insertion in children presenting for elective surgery.

Key words: $\quad$ LMA, Laryngeal Mask Airway, Propofol, Ketofol.

Article Citation: Ahmed H, Tariq A, Sagheer A, Ahmad A, Aslam S. Frequency of excellent Laryngeal mask airway insertion conditions in children undergoing elective surgery: A comparison of propofol with ketofol. Professional Med J 2020; 27(3):607-612. DOI: 10.29309/TPMJ/2020.27.3.3738

\section{INTRODUCTION}

Securing and maintaining a patent airway are the corner stones of the anesthesia care, though health care providers other than anesthetists should master this skill as well. In order to provide adequate ventilation and thus oxygenation a good airway control is mandatory and it is part and parcel of safe anesthesia practice. ${ }^{1}$ With the advancement in anesthesia care certain new devices and techniques for securing airway have been introduced, among these are the supraglottic airway devices such as laryngeal mask airway, I-gel etc. As compared to the technique and advanced level of clinical skill required for endotracheal intubation these devices can be inserted with less level of training. ${ }^{2}$
LMAs have been used widely during general anesthesia, they have certain benefits over conventional bag mask ventilation in terms of freeing anesthetist's hands and lesser complications. ${ }^{3}$ Rather than crossing the vocal cords like endotracheal tube it sits over the cords. It is equally useful both in elective and emergency surgeries as well in adults and children. ${ }^{4}$ As evidence based practice, supraglotic airway devices are now part and parcel of difficult airway management protocols which are in practice all over the world. ${ }^{5}$

Propofol (2,6 di isopropylphenol ) is a central nervous system depressant acting through $\mathrm{GABA}_{\mathrm{A}}$ receptor activation and inhibition of NMDA receptors. It provides sedation hypnosis and also 
a neuromodulator. Its emulsion preparations contain preservatives. It is used widely in operation theatres and in ICUs. ${ }^{6}$

Ketamine is a racemic mixture that exerts its effects via NMDA receptors. Its degradation produces an active end product. These days its clinical uses range from anesthesia, analgesia to procedural sedation. However its psychological side effects are undesireable. ${ }^{7}$

Ketofol is a mixture of ketamine and propofol in different ratios. This combination allows reduction in total dose of propofol administered. It has a better safety profile in terms of cardiorespiratory complications. ${ }^{8}$ In small doses along with other sedative hypnotics as used in ketofol it causes minimal hallucinations. ${ }^{9}$

The LMA is most commonly placed using propofol as only anesthetic drug, it provides adequate muscle relaxation required for insertion. Use of propofol is associated with some adverse effects, most important being cardiorespiratory i-e hypotension, cough, laryngospasm, prolonged apnea. Pain at injection site is also common. ${ }^{4}$ These hemodynamic effects become more marked during LMA insertion as dose required for relaxation is often greater than the recommended dose for inducing anesthesia. ${ }^{10}$ Adverse effects associated with deeper levels of anesthesia achieved with some induction agents especially propofol can lead to fatal events in pediatric population. On the other hand minimizing induction dose as a protective strategy can itself trigger coughing, gagging and/or laryngospasm. ${ }^{11}$ This necessitated either switching to another induction agent or addition of an adjunct which can counter these unwanted effects in children. ${ }^{12}$ For this sake different co-induction agents have been used with propofol, these include ketamine, fentanyl and butorphanol. ${ }^{13}$

Ketamine has multidimensional clinical effects. It has gained its place as a co-induction agent. It is a sympathomimetic agent leading to increased heart rate and blood pressure. In addition ventilatory drive is minimally effected, and airway reflexes are preserved but at the same time muscle tone and secretions are increased. Its analgesic properties are very useful. ${ }^{14}$

Considering the pharmacological characters of these two drugs, it has been observed that their combination results in a balanced profile regarding cardiorespiratory complications in the patients. ${ }^{15}$

It is the first study of its kind in this institute. Aim of this study is to identify better drug among propofol and ketofol in terms of ease of laryngeal mask airway insertion in pediatric patients.

\section{MATERIAL AND METHODS}

This randomized control trial was conducted at the departments of anesthesia and intensive care Allied Hospital and Aziz Fatimah Hospital from 01-01-2017 to 30-06-2018.

Consecutive non-probability sampling technique was used. A total of $230^{16}$ (by using WHO sample size calculator for 2 proportions; $\mathrm{P} 1=68 \%, \mathrm{P} 2=52 \%$, power of study $=80 \%$, level of significance $=5 \%$ ) ASA I and ASA II patients (children), presenting for elective surgery to be done under General anesthesia using LMA , ranging from 1 to 12 years and weighing $5-30$ $\mathrm{kg}$, Mallampati class I and II were enrolled in the study. Informed consent was duly signed by the parents. Patients with difficult airways, those having allergies to propofol, ASA class III and IV, risk of regurgitation, presenting for emergency surgery were excluded from the study.

Children were divided into two groups using randomization method. Each group consisted of 115 patients. Group $\mathrm{P}$ received propofol alone and group KP received ketamine and propofol combination.

Intravenous induction agents were prepared in 10 $\mathrm{ml}$ syringes, for group $(\mathrm{P}) 1 \%$ Propofol was mixed with $20 \mathrm{mg}$ lidocaine hydrochloride and for group (KP) propofol and ketamine 2:1 ratio mixture was prepared. Basic monitors applied to the patients and intravenous fluid started. All patients were pre-oxygenated and Intravenous injection atropine $0.01 \mathrm{mg} / \mathrm{kg}$ and injection nalbuphine 0.2 
$\mathrm{mg} / \mathrm{kg}$ were given before induction agent. Both induction agents were administered in incremental doses till the loss of verbal contact with patients. Appropriate size LMA was administered 60 seconds later. Additional boluses of the induction agent were administered in $0.5 \mathrm{ml}$ aliquots to deepen the anesthesia whenever required.

Excellent LMA insertion conditions were assessed in terms of jaw relaxation and adverse response to airway manipulation.

Following scoring system was used. ${ }^{17}$

\begin{tabular}{|l|l|l|l|l|}
\hline \multicolumn{1}{|c|}{ Variables } & Score $\mathbf{0}$ & Score 1 & $\begin{array}{c}\text { Score } \\
\mathbf{2}\end{array}$ & $\begin{array}{c}\text { Score } \\
\mathbf{3}\end{array}$ \\
\hline $\begin{array}{l}\text { Jaw relaxation } \\
\text { (mouth opening) }\end{array}$ & $\begin{array}{c}\text { Unable } \\
\text { to open }\end{array}$ & $\begin{array}{c}\text { Minimally } \\
\text { open }\end{array}$ & $\begin{array}{c}\text { Half } \\
\text { open }\end{array}$ & $\begin{array}{c}\text { Fully } \\
\text { open }\end{array}$ \\
\hline $\begin{array}{l}\text { Coughing and } \\
\text { gagging }\end{array}$ & Severe & Moderate & Mild & Nil \\
\hline $\begin{array}{l}\text { Involuntary limb } \\
\text { movements }\end{array}$ & Severe & Moderate & Mild & Nil \\
\hline
\end{tabular}

Adverse response to airway manipulation is graded as

- Mild: Transient and minimal lasting $<5$ seconds

- Moderate: Lasting $>5$ seconds but resolved spontaneously within 20 seconds

- Severe: Sustained $>20$ seconds or required additional boluses of drugs

The numerical insertion score was obtained by summing up the scores assigned to the factors: jaw relaxation, coughing and gagging and involuntary limb movements. The maximum score is thus 9 while the minimum score is 0 .

The qualitative insertion scores are as follows ${ }^{17}$ :

\begin{tabular}{|l|c|}
\hline \multicolumn{1}{|c|}{ LMA insertion conditions } & Score \\
\hline Excellent & $7-9$ \\
\hline Good & $4-6$ \\
\hline Poor & $0-3$ \\
\hline
\end{tabular}

Anesthesia was maintained with $\mathrm{N}_{2} \mathrm{O} / \mathrm{O}_{2}$ in a ratio of $50 \%: 50 \%$ and isoflurane (1.3\%) in both groups. Continuous monitoring of vital signs done throughout the procedure. After recovery patients were observed in post anesthesia care unit before shifting to the ward till Modified Aldrete score is $9 / 10$.

\section{Data Collection}

LMA insertion conditions in terms of jaw relaxation and adverse response to airway manipulation (coughing and gagging, involuntary limb movements) were recorded and score assigned as per designed scoring system. Insertion of supraglottic device was done by a trained anesthesiologist who was blinded to the drug preparation. Similarly anesthesiologist who collected data was also blinded to the drug used. Data was collected on a specified proforma.

\section{Data Analysis}

All the collected data was entered into SPSS version 20 and analyzed. The qualitative data like gender, ASA grade, Mallampati class and excellent LMA insertion conditions were presented as frequency and percentage. Quantitative data like age, weight and total score was presented as means and standard deviations. Chi-square test was applied to compare excellent LMA insertion conditions between two groups. Effect modifiers like age, gender, weight, ASA grade and Mallampati class controlled by stratification. Post stratification chi-square test was applied. P value $<0.05$ was taken as significant.

\section{RESULTS}

Mean age was calculated as $6.96 \pm 2.02$ years in Group-P and $7.14 \pm 2.13$ years in Group-KP (Table-I).

\begin{tabular}{|l|c|c|c|c|}
\hline $\begin{array}{c}\text { Age } \\
\text { (in Years) }\end{array}$ & \multicolumn{2}{|c|}{$\begin{array}{c}\text { Group-A } \\
(\mathbf{n = 1 1 5})\end{array}$} & \multicolumn{2}{c|}{$\begin{array}{c}\text { Group-B } \\
(\mathbf{n = 1 1 5})\end{array}$} \\
\cline { 2 - 5 } & $\begin{array}{c}\text { No. of } \\
\text { Patients }\end{array}$ & $\%$ & $\begin{array}{c}\text { No. of } \\
\text { Patients }\end{array}$ & $\%$ \\
\hline $1-6$ & 54 & 46.96 & 49 & 42.61 \\
\hline $7-12$ & 61 & 53.04 & 66 & 57.39 \\
\hline Total & 115 & 100 & 115 & 100 \\
\hline Mean+SD & \multicolumn{2}{|c|}{$6.96+2.02$} & \multicolumn{2}{|c|}{$7.14+2.13$} \\
\hline
\end{tabular}

Weight in Group-P was calculated as $21.48 \pm 5.69$ kgs and in Group-KP as21.94 26.00 kgs (Figure-I). 


\section{Mean weight}

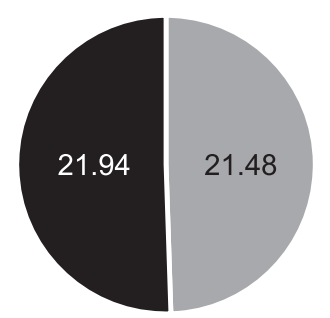

Group P Group PK

Figure-1. Mean weight $(\mathrm{kg})$ of the patients

53.04\% $(n=61)$ in Group-P and 35.65\% $(n=41)$ in Group-KP did not show excellent conditions for LMA insertion. Whereas $46.96 \%(n=54)$ in Group-P and $64.35 \%(n=74)$ in Group-KP had excellent LMA insertion conditions. $p$ value was calculated as 0.007 showing a significant difference (Figure-2).

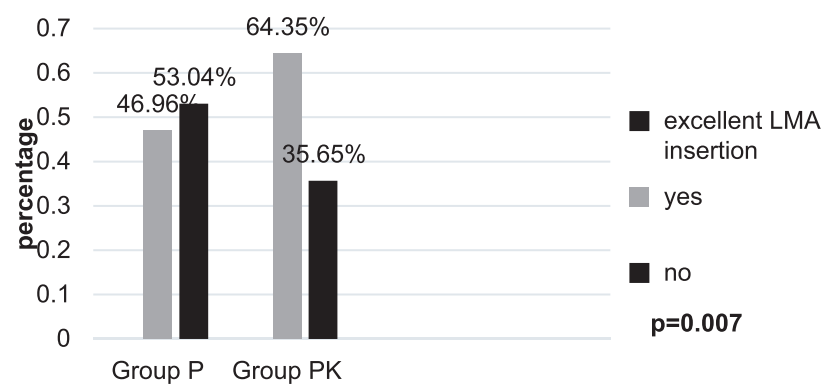

Figure-2. Comparison of excellent LMA insertion conditions in children: Comparison of propofol with ketofol

\section{DISCUSSION}

The age and weight of the patients in both groups were comparable. The results of our study showed that 54 out of 115 patients in Group-P, who received injection propofol as an induction agent, and 74 out of 115 patients in Group-KP, who received ketofol as induction agent showed excellent LMA insertion conditions. The $p$ value was calculated as 0.007 which shows significant results. These results are similar to the study conducted by Yousef GT and Elsayed $\mathrm{KM}^{16}$ which showed excellent condition for insertion of laryngeal mask airway in KP group 90\% $(n=45)$ as compared to $P$ group $76 \%(n=38)$. They also recorded that a faster Induction time and less painful administration of drug in KP group as compared to $P$ group. Another observation was stable haemodynamics and shorter apnea time in KP group as compared to $P$ group. ${ }^{17}$

The results of our study are also comparable to another done for insertion of laryngeal tubes under propofol or ketofol anesthesia. They showed significant results with $\mathrm{p}<0.05$ with better insertion of laryngeal tube with minimal adverse airway responses and complications under ketofol (Group K ) induction as compared to propofol (Group P). ${ }^{18}$

Goel S. also showed better insertion of LMA in Group PK (ketofol) and Group PM (propofol+midazolam) than in Group $P$ (propofol) ${ }^{19}$ which is also confirmed in our study.

Another study by Abbera B. et al did not elicit preference of one drug over other in terms of LMA insertion conditions. $P$ value calculated for their study was 0.681 which was insignificant. Though in terms of mean arterial blood pressure and duration of apnea ketofol was better than propofol. ${ }^{20}$ Another study showed results contrary to ours with no significant difference between two groups for jaw relaxation and adverse airway reflexes in elderly patients. ${ }^{21}$

Gupta A et al also showed PK (propofol-ketamine) group with least success in $n=12(40 \%)$ patients as compared to 13 (43.33\%) patients in Group PF (propofol- fentanyl) and in 26 (86.67\%) patients in Group PB (propfol- botarphanol). ${ }^{12}$

\section{CONCLUSION}

The results of this study concludes that use of ketofol provides excellent insertion conditions for LMA insertion in children presenting for elective surgery.

Current study covered only LMA insertion conditions under two different induction agents. It did not include haemodynamic variations associated with propol and ketofol. Another study which covers these two aspects in children should be conducted on our population.

Copyright $@ 20$ Oct, 2019. 


\section{REFERENCES}

1. Stewart JC, Bhananker S, Ramaiah R. Rapid-sequence intubation and cricoid pressure. Int J Crit IIIn Inj Sci. 2014 Jan; 4(1):42-9.

2. Amr YM, Amin SM. Comparison of two regimes of thiopental and propofol for I-gel supraglottic airway device insertion. Aneasth Essays Res. 2010 Jan-Jun; 4(1): 25-28.

3. Kim GW, Kim JY, Kim SJ, Moon YR, Park EJ, Park SY. Conditions for laryngeal mask airway placement in terms of oropharyngeal leak pressure: A comparison between blind insertion and laryngoscope-guided insertion BMC Anesthesiol. 2019; 19: 4.

4. Hosseinzadeh H, Golzari SEJ, Torabi E, Dehdilani $M$. Hemodynamic changes following anesthesia induction and LMA insertion with propofol, etomidate, and propofol + etomidate. J Cardiovasc Thorac Res. 2013; 5(3): 109-112.

5. Huang AS, Hajduk J, Jagannathan N. Advances in supraglottic airway devices for the management of difficult airways in children. Expert review of medical devices. 2016; 13(2):157-69.

6. Kotani Y, Shimazawa M, Yoshimura S, Iwama T, Hara $\mathrm{H}$. The experimental and clinical pharmacology of propofol, an anesthetic agent with neuroprotective properties. CNS Neurosci Ther. 2008; 14(2):95-106.

7. Amornyotin S. Ketamine: Pharmacology revisited. International journal of Anesthesiology Research. 2014(2):42-44.

8. Amornyotin S. Ketofol: A combination of ketamine and propofol. Med Crave Journal of Anesthesia \& Critical care. 2014; 1(5).

9. Ghadami YA, Ayatollahi V, Hashemi A, Behdad Sh, Ghadami YE. Effect of two different concentrations of propofol and ketamine combinations (Ketofol) in pediatric patients under lumbar puncture or bone marrow aspiration. Iran J Ped Hematol Oncol. 2013; 3(1):187-92.

10. Al-Metwalli RR. The optimal effect-site concentration of sufentanil for laryngeal mask insertion during induction with target-controlled propofol infusion at 4.0 $\mathrm{g} / \mathrm{MI}$. Saudi J Anaesth. 2014 Apr; 8(2):215-9.

11. Ghatak T, Singh D, Kapoor R, Bogra J. Effects of addition of ketamine, fentanyl and saline with Propofol induction on hemodynamics and laryngeal mask airway insertion conditions in oral clonidine premedicated children. Saudi J Anaesth. 2012; 6(2):140.
12. Gupta A, Kaur S, Attri JP, Saini N. Comparative evaluation of ketamine-propofol, fentanyl-propofol and butorphanol-propofol on haemodynamics and laryngeal mask airway insertion conditions. $J$ Anaesthesiol Clin Pharmacol. 2011; 27(1):74.

13. Nagalakshmi $P$, Leo $S$, Uthirapathi $S$. Use of butorphanol, fentanyl, and ketamine as co-induction agents with propofol for laryngeal mask airway insertion: A comparative study. Anesth Essays Res. 2018 Jul-Sep; 12(3):729-734.

14. Kurdi MS, Theerth KA, Deeva RS. Ketamine: Current applications in anesthesia, pain, and critical care. Anesth Essays Res. 2014 Sep-Dec; 8(3): 283-290.

15. Jalili M, Bahreini M, Irani AD, Masoomi R, Arbab M, Mirfazaelian H. Ketamine-propofol combination (ketofol) vs propofol for procedural sedation and analgesia: Systematic review and meta-analysis. The American Journal of Emergency Medicine. 2016:13(3):558-69.

16. Comparison of propofol (1\%) with admixture (1:1) of thiopentone $(1.25 \%)$ and propofol $(0.5 \%)$ for laryngeal mask airway insertion in children undergoing elective eye surgery: Double-masked randomized clinical trial. Sinha K, Shenede D, Garg R. Indian J Anaesth. 2010:54:104-8.

17. Yousef GT, Elsayed KM. A clinical comparison of ketofol (ketamine and propofol admixture) versus propofol as an induction agent on quality of laryngeal mask airway insertion and hemodynamic stability in children. Anesth Essays Res. 2013 May-Aug; 7(2): 194199.

18. Ozgul U, Begec Z, Karahan K, Erdogan MA, Aydogan MS, Colak C, et al. Comparison of propofol and ketamine-propofol mixture (ketofol) on laryngeal tube-suction ii conditions and hemodynamics: A randomized, prospective, double-blind trial. Curr Ther Res Clin Exp. 2013 Dec; 75: 39-43.

19. Goel $\mathrm{S}^{1}$, Bhardwaj N, Jain K. Efficacy of ketamine and midazolam as co-induction agents with propofol for laryngeal mask insertion in children. Paediatr Anaesth. 2008 Jul; 18(7):628-34.

20. Aberra B, Aregawi A, Teklay G, Tasew H. Effect of ketofol versus propofol as an induction agent on ease of laryngeal mask airway insertion conditions and hemodynamic stability in pediatrics: An observational prospective cohort study. BMC Anesthesiol. 2019; 19:41. 
21. Erdogan $M^{1}$, Begec Z, Aydogan MS, Ozgul U, Yucel A, Colak C, Durmus M. Comparison of effects of propofol and ketamine-propofol mixture (ketofol) on laryngeal mask airway insertion conditions and hemodynamics in elderly patients: A randomized, prospective, double-blind trial. J Anesth. 2013 Feb; 27(1):12-7.

\begin{tabular}{|c|c|c|c|}
\hline \multicolumn{4}{|c|}{ AUTHORSHIP AND CONTRIBUTION DECLARATION } \\
\hline Sr. \# & Author(s) Full Name & Contribution to the paper & Author(s) Signature \\
\hline 1 & Humaira Ahmad & \multirow{5}{*}{$\begin{array}{l}\text { All authors contributed } \\
\text { equally towards the paper }\end{array}$} & $v^{2}$ \\
\hline 2 & Amna Tariq & & \\
\hline 3 & Asif Sagheer & & $A \operatorname{sरn}$ \\
\hline 4 & Aisha Ahmad & & \\
\hline 5 & Samina Aslam & & \\
\hline
\end{tabular}

